\title{
Las apolipoproteinas predicen mejor el riesgo cardiovascular que el colesterol
}

\section{Apolipoproteins are better cardiovascular risk predictors than serum cholesterol}

\section{Objetivo}

Comparar a las apolipoproteínas con el colesterol para predecir el primer infarto agudo de miocardio (IAM).

\section{Diseño, lugar y participantes}

Estudio de casos y controles llevado a cabo en 262 centros de 52 países de todos los continentes que incluyó 27.098 participantes. Se midieron lípidos en sangre (sin ayuno) de 9.345 casos (pacientes cursando su primer IAM, dentro de las 24 hs de iniciados los síntomas) y 12.120 controles reclutados en el ámbito hospitalario y la comunidad, sin antecedentes coronarios, y apareados* por sexo y edad.

Evaluación de los factores de riesgo y medición de resultados Se obtuvo información sobre factores demográficos, socioe-

Tabla 1: riesgo atribuible poblacional y OR por grupo etario para infarto agudo de miocardio de acuerdo al cociente entre ApoB/A1 y el de colesterol Total/HDL-colesterol.

\begin{tabular}{|c|c|c|c|}
\hline & & ApoB/ ApoA1 & Colesterol total/HDL-c \\
\hline \multirow{6}{*}{$\begin{array}{l}\text { Porcentaje de riesgo } \\
\text { poblaciónal atribuible } \\
\text { (e IC95\%) } \\
\text { a cada factor de riesgo }\end{array}$} & Europeos & $42,5 \%(33,8$ a 51,8$)$ & $29,7 \%(21,8$ a 39,0$)$ \\
\hline & Chinos & $44,4 \%(39,0$ a 49,9$)$ & $30,5 \%(24,0$ a 38,0$)$ \\
\hline & Sudasiáticos & $65,2 \%(54,9$ a 74,2$)$ & $32,3 \%(19,2$ a 48,9$)$ \\
\hline & Latinoamericanos & $46,4 \%(31,9$ a 61,5$)$ & NR \\
\hline & Arabes/Persas & $66,8 \%(56,3$ a 75,9$)$ & $45,6 \%(32,7$ a 59,2$)$ \\
\hline & Africanos negros & $70,9 \%(54,0$ a 83,4$)$ & $49,1 \%(30,9$ a 67,6$)$ \\
\hline \multirow{5}{*}{$\begin{array}{c}\text { Asociación } \\
\text { (OR IC95\%) } \\
\text { entre ambos } \\
\text { predictores y la probabilidad } \\
\text { de IAM por edad }\end{array}$} & Menores de 45 & $1,76(1,63$ a 1,89$)$ & $1,18(1,11$ a 1,25$)$ \\
\hline & 45 a 55 años & $1,70(1,59$ a 1,81$)$ & $1,23(1,16$ a 1,30$)$ \\
\hline & 56 a 65 años & $1,59(1,49$ a 1,70$)$ & $1,22(1,14$ a 1,30$)$ \\
\hline & 66 a 70 anos & $1,52(1,37$ a 1,69$)$ & $1,08(0,98$ a 1,18$)$ \\
\hline & Mayores de 70 & $1,24(1,13$ a 1,35$)$ & $0,98(0,9$ a 1,07$)$ \\
\hline
\end{tabular}

NR: No reportado. OR: odds ratio. IAM: infarto agudo de miocardio.

\section{Conclusiones}

La relación ApoB/A1 superó cualquier otra medida lipídica para predecir el primer infarto agudo de miocardio (IAM) en diferentes regiones geográficas, etnias, sexo y edad.

Palabras claves: colesterol, apolipoproteinas, riesgo cardiovascular, infarto agudo de miocardio. Key words: cholesterol, apoliproteins, cardiovascular risk, acute myocardial infarction. Fuentes de financiamiento: Canadian Institute of Health Research.

\section{Comentario}

La relación $\mathrm{ApoB} / \mathrm{A} 1$ conserva su poder predictivo en todas las edades -lo que no ocurre con otras determinaciones lipídicas pero dada la magnitud del cambio que implicaría en la práctica clínica, habría que corroborar estos hallazgos con estudios prospectivos. De éstos, el más grande hasta la fecha -175.000 participantes de un programa salud sueco seguidos por cinco años, - reportó cerca de dos mil muertes cardiovasculeres y también determinó que la relación $A p o B / A 1$ era mejor a las mediciones convencionales, pero los únicos factores de riesgo medidos fueron los marcadores lipídicos. conómicos y de riesgo cardiovascular. Se tomaron muestras de sangre en las primeras 24 horas del ingreso. Como medida de riesgo se utilizó el Odds ratio (OR) ajustado* y el riesgo atribuible poblacional (RAP)* con un IC95\% para cada medición lipídica.

\section{Resultados principales}

La relación apolipoproteínas B/A1 (ApoB/A1) superó cualquier medida lipídica (considerada individualmente o como medida lipídica convencional (LDL-colesterol/HDL-colesterol, $p<0,0001)$. Los análisis de subgrupo, posibles por su gran tamaño muestral, evidenciaron la superioridad de la relación ApoB/A1 en ambos sexos, en todos los grupos étnicos y edades. Ver tabla 1.

Agustín Ciapponi [ Servicio de Medicina Familiar y Comunitaria. Hospital Italiano de Buenos Aires. agustín.ciapponi@ hospitalitaliano.org.ar ]

\section{Conclusión del comentador}

Las apolipoproteínas pueden ser medidas de manera normalizada y automática a un costo cercano al de los lípidos tradicionales y sin necesidad de ayuno. Aunque su uso mejoraría la predicción de riesgo, los médicos y pacientes han tardado décadas en aprender a medir y tratar las dislipidemias, por lo que demandaría un gran esfuerzo educativo sustituir las mediciones lipídicas tradicionales por estas posiblemente mejores apolipoproteínas, justificándose evaluar la costo-efectividad incremental del cambio.

Ciapponi A. Las apolipoproteínas predicen mejor el riesgo cardiovascular que el colesterol. Evid. actual. práct. ambul; 11(5): 141, Sep-Oct.2008 Comentado de: McQueen MJ y col. ipids, lipoproteins, and apolipoproteins as risk markers of myocardial infarction in 52 countries (the INTERHEART study): a case-control study. Lancet 2008;372(9634):224-33. PMID: 18640459.

\section{Referencia}

1. Navarro M, y col. Los factores de riesgo modificables en la enfermedad cardiovascular son similares en 52 países. Evid.actual.práct.ambul. 2005;14-15. Comentado de Effect of potentially modifiable risk factors associated with myocardial infarction in 52 countries (the INTERHEART study): case-control study. Yusuf S y col. Lancet 2004; 364:937-52. PMID: 15364185. El estrés psicosocial incrementa el riesgo de IAM. Comentado de: Association of psychosocial risk factors with risk of actue myocardial infraction in 11119 cases and 13648 controls from 52 countries (the INTERHEART study):case-control study. Rosengren A y col. Lancet 2004; $364: 953$-962. PMID: 15364186

2. Moller C y col. Impact of follow-up time and re-measurement of the electrocardiogram and conventional cardiovascular risk factors on their predictive value for myocardial infarction. J Intern Med 2006;260(1):22-30.

3. Walldius $\mathrm{G}$ y col. High apolipoprotein B, low apolipoprotein A-I, and improvement in the prediction of fatal myocardial infarction (AMORIS study): a prospective study. Lancet 2001;358(9298):2026-33.

4. Walldius G y col. Stroke mortality and the apoB/apoA-I ratio: results of the AMORIS prospective study. J Intern Med 2006;259(3):259-66.

5. Lind L. Apolipoprotein B/A1 and risk of cardiovascular disease. Lancet. 2008;372(9634):185-6.

6. Ingelsson E y col. Clinical utility of different lipid measures for prediction of coronary heart disease in men and women. Jama 2007;298(7):776-85. 